\title{
Corpo e masculinidade na revista VIP Exame*
}

\author{
Marko Monteiro*"
}

\begin{abstract}
Resumo
Nesse artigo elaboro comentários teóricos acerca de novas formas de se vivenciar a corporalidade presentes contemporaneamente, a partir da análise da revista masculina VIP Exame. O texto baseiase numa pesquisa que incluiu uma observação dentro da redação da revista e análise de materiais impressos, centrando-se na forma como a revista aborda o corpo masculino e coloca a preocupação com a aparência como importante para uma masculinidade bem sucedida. Com base nestes dados busco avaliar, a partir de perspectivas feministas e sobre o corpo, a influência do valor dado ao corpo $e$ ao seu monitoramento reflexivo na constituição de identidades de gênero.
\end{abstract}

Palavras-chave: Masculinidade, Corpo, Revistas Masculinas, Teoria Feminista, Reflexividade

\footnotetext{
* Recebido para publicação em março de 2001.

** Doutorando em Ciências Sociais, IFCH, Unicamp.
} 
Corpo e masculinidade na revista VIP Exame

Body and Masculinity in the Magazine VIP Exame

\begin{abstract}
In this article I elaborate theoretical comments on the subject of corporeality and the new forms of experiencing the body that are present in contemporary times. On the basis of a research with a Brazilian men's magazine, VIP Exame, which involved the analysis of issues of the magazine as well as an observation of the working process of the reporters and journalists, I focus my comments on the way the masculine body is treated by the magazine and how a discourse emerges on masculinity where attention to "good looks" becomes an important feature of a successful masculinity. On the basis of these observations I go on to discuss feminist and other theories of the subject, in order to understand how the reflexive monitoring of the body is increasingly important in the constitution of gender identities.
\end{abstract}

Key words: Masculinity, Body, Men's Magazines, Feminist Theory, Reflexivity. 
Marko Monteiro

\section{Introdução}

Este trabalho aborda, a partir da análise da revista masculina VIP Exame, questões referentes a como o corpo masculino é compreendido na contemporaneidade. A partir desse recorte empírico específico, vinculado a uma pesquisa com revistas masculinas ${ }^{1}$, trato de abrir alguns caminhos para a discussão.

Valendo-me da análise da revista e de observações feitas na redação, coloco algumas questões a respeito de novas formas de perceber o corpo, e de como ele se torna crescentemente importante na constituição de identidades masculinas. Em outras palavras, exploro como o corpo pode ser analisado como "meio" para a cultura ${ }^{2}$, como locus onde são constituídas as identidades de gênero, a partir da discussão da VIP Exame, particularmente da maneira como os cuidados com o corpo masculino são nela apresentados como adequados ao homem moderno.

A revista é um objeto interessante para este tipo de discussão por trazer uma proposta de inovação para o mercado editorial brasileiro: uma linha que, centrada na moda, saúde, beleza e comportamento, tem como alvo o público masculino heterossexual. Exatamente por ter esta proposta inovadora, ela aponta para possíveis novas direções em termos de construções de masculinidade, associadas a esse grupo, socialmente importante, constituído por homens heterossexuais e de classe

1 Essa pesquisa faz parte de um trabalho maior que desenvolvi em minha dissertação de mestrado em Antropologia Social na Unicamp, defendida em 2000, intitulada Masculinidade em Revista: Uma análise da VIP Exame, Sui Generis e Homens. No caso da VIP Exame, assim como das outras revistas, a pesquisa envolveu observações in loco na redação da revista (Editora Abril em São Paulo), assim como análise de conteúdo de 5 exemplares publicados no período em que foi realizada a observação, em 1998.

2 Bordo, Susan. The Body and the Reproduction of Femininity: A Feminist Appropriation of Foucault. In: JAGGAR, Alison M. and BORDO, Susan. (eds.) Gender/Body/Knowledge: Feminist Reconstructions of Being and Knowing. New Brunswick, Rutgers University Press, 1989, pp.13-33. 
alta. As construções de masculinidade associadas a outros grupos de homens não têm as mesmas características (analisá-las, demandaria outras pesquisas). Por isso me atenho nesse trabalho a uma publicação voltada para um público específico, de forma a colocar algumas questões de ordem metodológica a respeito do corpo e da masculinidade nos dias de hoje.

A revista segue padrões editoriais já consagrados em publicações femininas. Como afirmam os editores e repórteres, na $V I P$, esses padrões foram adaptados para o público masculino heterossexual no país. Ao deslocar uma fórmula associada ao público feminino para esse nicho específico de público, os jornalistas colocam em questão conceitos arraigados a respeito de seu público alvo, como mostro adiante, no que tange à masculinidade. Essas novas formas de perceber o masculino podem ser compreendidas considerando aquilo que Giddens chamou de reflexividade. ${ }^{3}$ Essa reflexividade pode ser interpretada, ao meu ver, como um sintoma do descentramento ${ }^{4}$ da masculinidade contemporânea, que perde uma referência unificada, válida para todos os homens, e se pauta crescentemente por valores múltiplos e nem sempre coerentes.

Não sugiro aqui que não haja grupos de homens dominantes sobre outros e sobre mulheres, ou que não exista mais a "masculinidade" como um atributo ao qual os homens ainda hoje buscam se associar. Argumento, sim, que a existência de uma "masculinidade", um referencial único, imutável e coerente de identidade que pode ser considerado legítimo e aceitável para todos os homens, não faz sentido nos tempos atuais. Como exemplo, parto da minha pesquisa com a VIP, buscando mostrar como as identidades dos homens, sejam de gênero ou outras, são crescentemente constituídas por referenciais múltiplos, em

3 Giddens, Anthony. Modernity and Self Identity: Self and Society in the Late Modern Age. Cambridge, Polity, 1991.

4 Hall, Stuart. A Identidade Cultural na Pós-modernidade. Rio de Janeiro, DP\&A, 1998. 
Marko Monteiro

contextos localizados e, ao mesmo tempo, em contato com referenciais globalizados.

\section{A revista VIP Exame}

A revista VIP Exame é publicada, aproximadamente, há 21 anos - durante 13 anos foi encarte especial da revista Exame (de negócios). A VIP apresenta a proposta mais original de revista masculina para heterossexuais no mercado editorial brasileiro, fugindo do padrão de revistas como a Playboy ou Placar, que centram suas pautas em esportes, negócios e ensaios fotográficos de mulheres nuas. Na VIP o sexo ainda é o elemento mais importante do conteúdo das reportagens (não diferindo muito das revistas femininas); as mulheres, mostradas em profusão, nunca aparecem totalmente nuas e a abordagem dada aos textos e às matérias é diferente de revistas mais tradicionais já citadas.

Muitas matérias discutem o que as mulheres querem $e$ esperam dos homens, a saúde sexual e reprodutiva do homem $e$ beleza e moda. De alguma forma, todas as matérias se direcionam, como veremos adiante, ao homem que deseja mulheres e quer agradá-las ao máximo. O consumo também é um elemento importante da revista. Matérias sobre livros, CDs, carros importados, entre outras, oferecem ao leitor as últimas tendências em termos de consumo de alto padrão.

Este perfil da revista pode ser traçado a partir daquilo que os editores falam a respeito da revista $e$ do discurso da revista acerca de si própria (por exemplo, em editoriais). Nas minhas conversas com os editores, era sempre enfatizado o "diferencial VIP Exame" no tratamento dos assuntos tidos como masculinos - consumo, mulheres e aparência. Eles caracterizam este diferencial como uma abordagem mais engraçada, bem humorada $e$ inteligente, sem "baixar o nível", sem recorrer a sensacionalismos e a um apelo exagerado à sexualidade. Por isso mesmo todos os ensaios com a "garota da capa" nunca são de nudez total (característica marcante daquilo que se concebe no mercado como revista 
Corpo e masculinidade na revista VIP Exame

masculina, cujos melhores exemplos são Playboy, Ele Ela, Sexy e Brazil). Marco Rezende, Diretor de Redação, reflete de forma completa, em editorial, o discurso da revista sobre seu perfil:

VIP nasceu há 17 anos, como suplemento da revista EXAME, $e$ há quase quatro anos ganhou vida independente. Os assinantes mais antigos, mas também os leitores que a descobriram recentemente, notaram que nos últimos meses houve uma série de mudanças na revista. VIP ficou visualmente mais atraente. Ganhou uma estrutura ágil, movimentada, de leitura mais fácil. Tem novos colunistas e novas seções. Tornou-se uma revista mais completa, instigante, divertida, útil. $\mathrm{E}$ persegue objetivos declarados de qualidade e elegância. Tudo isso faz dela, hoje, a mais moderna publicação masculina do país.

Não se faz uma boa revista sem uma missão editorial clara, uma equipe capaz e uma preocupação central com as necessidades, ambições e desejos do leitor. Na sua reforma editorial, VIP definiu o seu foco no universo de interesses do homem. Construiu uma pequena e afinada equipe de jornalistas, designers gráficos e colaboradores. O resultado de um trabalho feito com empenho, profissionalismo $e$ criatividade pode ser medido pelo impacto da revista no mercado publicitário e no meio editorial e, mais importante, pelo aumento da circulação e da aceitação dos leitores.

O objetivo de VIP é ser, a seu modo, uma revista indispensável para o homem inteligente. Se você está preocupado com a sua saúde e boa forma, se você gosta de carros e de se vestir bem, se tem interesse por esporte, viagens, comida e outras coisas boas (inclusive bom humor), então VIPé a sua revista.

Há outro tema importante, crucial, que a nova VIP trata com alegria, o do relacionamento entre o homem $e$ a mulher. Aliás, completando a frase com os necessários adjetivos: o complicado, inevitável, delicioso relacionamento entre o homem e a mulher. Com reportagens, ensaios e testes que procuram ser ao mesmo tempo úteis e divertidos, a revista quer desvendar para o 
Marko Monteiro

homem as motivações $e$ os gostos femininos. VIP acredita que o homem que quer viver bem quer viver bem em primeiro lugar com sua mulher ou namorada. Se você também acha, como nós que fazemos a revista, que a vida é feita de qualidade e atitude, bom humor e entusiasmo, considere a nova VIP como um perfeito guia para as suas escolhas de homem. ${ }^{5}$

Além de mapear de forma bastante completa a gama de interesses coberta pela revista, o editorial menciona um dado importante - a reforma editorial que sofreu a revista em meses recentes, anteriores ao período da minha observação. Segundo Mariella Lazaretti, uma das envolvidas no projeto de reformulação, o objetivo era tornar a revista mais ágil, e mudar seu público alvo para um segmento mais jovem. Se a antiga VIP se dirigia a executivos com mais de 40 anos, a "nova VIP' busca o leitor entre 25 e 45 anos, o que pressupõe um tratamento diferenciado, que vai desde reformas no visual da revista até o uso de uma linguagem mais informal.

O novo modelo foi implementado porque a proposta antiga não estava funcionando muito em termos de público $e$ publicidade. "A revista tinha a pretensão de ser chique, mas não conseguia ser", disse Mariella. Ela, Paulo Nogueira (chefe do grupo Exame, do qual a VIP faz parte) e José Ruy Gandra, ao participarem do processo de reconstrução da proposta editorial da revista, consultaram as revistas masculinas de sucesso no exterior - entre outras, Maxim e Details - para ver o que estava "funcionando" e adaptar para o contexto brasileiro e notaram que o sucesso era alcançado com um estilo mais jovem, mais bem humorado, mais irônico, mais "escrachado", menos ingênuo e menos politicamente correto, "para não ficar babaca".

O editorial acima permite perceber uma continuidade entre as temáticas das revistas tradicionais $e$ as da VIP, apesar de seus apelos à modernidade. A VIP ainda se pauta por uma oposição

5 VIP Exame, edição 158, ano 17, número 6, junho de 1998, p.7. 
Corpo e masculinidade na revista VIP Exame

rígida e "inevitável" entre homens e mulheres, segundo a qual "o homem que quer viver bem, quer viver bem, em primeiro lugar, com sua mulher ou namorada". A matriz heterossexual, portanto, é pressuposto básico em se falando de identidades de gênero ${ }^{6}$. A revista ancora-se, permanentemente, na idéia da heterossexualidade "natural" dos leitores. Isso é evidente no recurso da "garota da capa" para chamar a atenção do público masculino, além do uso constante de imagens de mulheres seminuas, com a quase ausência de imagens de homens, apelando ao sensual e ao sexual, mesmo que de forma mais "refinada" ou "inteligente", como os editores gostam de dizer. Nunca vemos homens nas capas. A revista não recorre ao uso explícito de nudez ou linguagem direta, mas há uma profusão de matérias sobre sexo, testes, fotos de mulheres de biquínis e roupas íntimas, entre outros artifícios.

Para ajudar todos os leitores nessa ocasião propícia, VIP foi perguntar diretamente às mulheres o que é que elas esperam de nós, homens, em 1998. É esse o tema de capa desta edição. Na prática, o complicado, o polêmico, o delicioso relacionamento homem/mulher tem sido um tema central da nossa VIP. Por motivo quase óbvio: seria impossível fazer uma revista masculina moderna, útil $e$ divertida ignorando o que, em última análise, interessa ao homem - a mulher. Sua cabeça. Seu corpo. Seus sentimentos. ${ }^{7}$

O pressuposto da heterossexualidade "natural" dos leitores se expressa nas inúmeras piadinhas que acompanham as imagens na revista, algo que se encontra de forma idêntica em uma revista estrangeira - Maxim. Um exemplo é o índice da edição 158.

${ }^{6}$ BuTLER, Judith. Gender Trouble: Feminism and the Subversion of Identity. New York and London, Routledge, 1990. Para mais comentários sobre este tema ver também DE LAURETIS, Teresa. Eccentric Subjects: Feminist Theory and Historical Consciousness. Feminist Studies, 16(1), Spring 1990, pp.115-151.

7 VIP Exame, edição 152, dezembro de 1997, p.15. 
Numa das fotos, dois homens flertam com uma mulher, e a legenda diz, insinuando um diálogo: "Fica comigo, gata, o cara aí curte outra praia". Em outra foto, de uma agenda eletrônica, a legenda explica: "Aqui cabem os telefones da Ivete [Sangalo, capa desta edição], da Tuca, da malasiana do 007". Esse aspecto, somado à abordagem bem humorada, mostra uma certa naturalidade no tratamento de qualquer tipo de assunto, especialmente o sexo e toda sua multiplicidade, o que seria um índice de "modernidade" da revista.

\section{O corpo masculino}

Mariella Lazaretti, editora da VIP, é responsável pela seção de saúde e de corpo. Em conjunto com o repórter Carlos Amoedo, ela elabora matérias e responde questões do leitor. Segundo ela, a proposta editorial da revista exige uma abordagem diferenciada da questão da saúde. Por exemplo, ao tratar do tema corpo, não se deve focalizar a doença, mas sim formas de manter e recuperar a saúde. Ela utilizou a revista Veja como contraponto "sério" à abordagem mais leve e bem humorada da VIP - se na Veja exploram os aspectos da doença e dos males que ela pode causar, como o câncer, a VIP aborda esses aspectos de maneira mais bem humorada, ainda que informativa.

Os temas comentados são relacionados à masculinidade, ou questões de saúde e de corpo que têm potencial interesse para os homens, como calvície e circuncisão. ${ }^{8}$ A editora considera que o homem sabe muito pouco sobre seu próprio corpo, mas está bastante interessado nesses assuntos. Por ser pouco tocado em revistas masculinas, se tornou um ponto de interesse a ser explorado pela VIP algo que faz parte da tradição das revistas femininas - falar de temas como o corpo e como conhecê-lo melhor, o que remonta aos anos 50.

8 Uma das reportagens que ela estava elaborando no período da minha pesquisa era uma matéria sobre fimose e circuncisão, e outra sobre como tomar banho. 
Para protagonizar a seção de dicas de saúde, a editora criou uma personagem fictícia. Trata-se de Eunice, uma enfermeira bastante sensual que responde as cartas do leitor sobre saúde, mas de forma lasciva, "bem biscatona", adicionando humor a uma seção nem sempre engraçada. Antes da introdução de Eunice, essa seção se chamava "Pronto Socorro" e não recebia muito retorno dos leitores. As aparições da enfermeira fizeram sucesso, a seção recebeu 12 cartas em um mês, um recorde e uma forte indicação da boa aceitação da personagem.

Para além do bom humor e da inovação na abordagem, considera-se que as respostas de Eunice devem ser sérias $e$ informativas. O fetiche da enfermeira "gostosona", segundo a editora, foi um diferencial que agradou os leitores, que gostam de receber atenção especial para o seu problema específico. A linguagem por ela utilizada é "vulgar", "espirituosa", mas "informativa". Esta é a abordagem que a editora considera como marca da VIP como um todo: bem humorada, mas com muita informação - uma revista que é "capaz de rir de si mesma", se aproximando, assim, do leitor.

A estréia de Eunice se deu com a matéria "Chame a enfermeira". ${ }^{9}$ Nela aparece um desenho de uma enfermeira em uma pose bastante sensual, de mini saias e sapatos de salto alto vermelhos. Ao lado da imagem, um pequeno texto: "Quero entrar na sua intimidade, benzinho. Escreve, vai...". Vejamos alguns exemplos de cartas por ela respondidas:

Nos dias seguintes aos churrascos surgem pequenas bolhas nas solas de meus pés e escamações nas mãos. Será que sou alérgico a carne? (Sílvio Bernardes, Campinas - SP)

Você precisa acabar com a mania de espalhar as brasas com os pés, bonitão. Ou, então, como disse José Carlos Mori, um amigo muito amigo, alergista do Hospital do Servidor Público do Estado de São Paulo, fazer testes para identificar se você é alérgico a algum corante ou aditivo

9 VIP Exame, edição 158, p.30. 
Marko Monteiro

químico da carne. Além disse, esse banquete de leão pode aumentar os níveis de ácido úrico em seu organismo e descamar suas mãos e pés. Veja se pega leve, na carne... ou tshhh, nas brasas.

Caminho sempre em jejum porque preciso perder peso. Mas ouvi falar que isso faz mal. È verdade? (Miguel Antunes, Poços de Caldas - MG).

Miguel, aposto que você já é um gatão assim mesmo, acima do peso, mas andei falando com o Osmar, sabe? O Osmar de Oliveira, médico esportivo, sobre seu caso. Ele diz que as caminhadas em jejum obrigam o organismo a usar os depósitos de gordura para gerar energia. Ou seja, aquele pneuzinho estepe da cintura pode ir a uso. Isso porque você não repõe os estoques de açúcar durante o sono. Assim, você emagrece de verdade. O caso, Miguel, é que com baixos índices de açúcar no sangue você pode se sentir mal. Se for seu caso, campeão, recomendo um suco de frutas antes de sair para a luta. ${ }^{10}$

$\mathrm{O}$ texto, que reflete as percepções da editora, mostra respostas bastante informais e sugere o desejo sexual da enfermeira em relação ao leitor que fez a pergunta. Mostra também a preocupação em citar especialistas da área de medicina - alergista e médico esportivo -, revelando a importância concedida à validade científica para dotar de valor jornalístico essas respostas.

Os artifícios usados pela revista para incentivar o interesse do leitor pelo seu próprio corpo mostram relações que são, também, evidentes nas percepções dos jornalistas sobre a linguagem adequada ao público masculino.

Aparentemente, a necessidade de cuidar de si e de seu corpo ainda não é óbvia o suficiente para o leitor, portanto, o interesse por tais matérias não foi tão imediato. Nos termos do Editor Chefe da revista: o leitor muitas vezes precisa ser ensinado

${ }^{10}$ ID., IB., pp.130-131. 
Corpo e masculinidade na revista VIP Exame

a gostar dos temas tratados na revista; de certa forma, o nicho de leitores é criado no decorrer do tempo. Muitas vezes, a abordagem dada por revistas estrangeiras, como eles dizem, é "adaptada" ao leitor brasileiro, cujo gosto é mais conservador.

A seção sobre dicas de saúde, voltada para responder ao leitor, era uma das menos lidas antes da aparição de Eunice. Somente obteve sucesso ao apelar para o desejo sexual dos leitores. Como enfatizou Mariella, o desejo de saber mais sobre o corpo existe, mas o difícil é acertar uma fórmula para estabelecer uma comunicação adequada com os leitores. No caso, a fórmula para estimular o leitor a participar da seção, "educando-o", foi deslocar sua atenção para a imagem da enfermeira "gostosona", considerada legítima e correta, utilizando uma vinculação entre sexualidade e masculinidade.

Podemos pensar que a preocupação com o corpo ainda é um tema pouco trabalhado no imaginário masculino, tido como pouco relevante e mesmo inadequado $e$, por isso mesmo, esse recurso facilita a abordagem da questão. $\mathrm{O}$ ponto que procuro destacar, porém, é que nossas "parcelas de mercado" precisam se relacionar com o universo de representações dos leitores. As propostas editoriais passam, portanto, pelo crivo do leitor e são constantemente readaptadas de forma a garantir que as idéias elaboradas na redação sejam transmitidas e obtenham resposta por parte dos leitores, em forma de cartas, telefonemas e e-mails.

Este tipo de adaptação discursiva, que busca tornar a preocupação com o corpo palatável ao imaginário masculino tradicional pode ser visto no seguinte exemplo:

Porque você é macho

Shiseido, tradicional marca japonesa de cosméticos, acaba de lançar uma linha masculina - Basala - que vai livrar a sua cara daqueles cremes perfumados e suspeitos feitos para o sexo frágil. [...] Mas o melhor de tudo é o cheiro dos produtos: um suave aroma cítrico que não mata ninguém 
Marko Monteiro

asfixiado e muito menos coloca a sua masculinidade na berlinda. ${ }^{11}$

Este é um recurso utilizado também na publicidade que a revista faz de si mesma:

Se você nunca abre a porta para as mulheres, está na hora de abrir esta revista.

VIP é a revista masculina sobre tudo o que o homem gosta de falar. Só que por escrito. Carros, roupas, vinhos, charutos, viagens, cuidados com o corpo, livros. Tudo o que é divertido. Para você não ser um daqueles chatos que só falam de trabalho. E como é uma revista para homens, evidentemente também fala da coisa mais importante para o homem: seu relacionamento com a mulher. Porque a revista é masculina, não machista. Compre a sua na banca mais próxima. ${ }^{12}$

Até mesmo os cosméticos têm que ser "adaptados" para serem considerados próprios para o uso dos homens. Ao mesmo tempo em que estimulam o conhecimento dos homens sobre beleza e cosméticos e a incorporação desses produtos no cotidiano, a revista os apresenta de maneira que não desestabilizem a separação entre homem e mulher. Os cremes "dela" têm perfume diferente e são impróprios para "ele", que necessita de cosméticos de "macho". Ao mesmo tempo em que o homem supostamente se feminiliza, ao usar cosméticos, os cosméticos se masculinizam, para manter intactas as divisões entre os gêneros.

A constante revisão de teorias científicas a respeito do corpo se expressa na matéria "Sexo sem cortes", sobre circuncisão:

${ }^{11}$ ID., IB., p.127.

12 ID., IB., p.133. 
Corpo e masculinidade na revista VIP Exame

Na última década firmou-se a idéia médica de que a retirada do prepúcio, a pele que cobre a extremidade do pênis (glande), a boa e velha circuncisão, seria bem-vinda a todos os homens que prezam a higiene íntima. Ela evita o acúmulo de secreções que podem causar infecções como doenças venéreas e até câncer - inclusive no colo do útero da parceira. Segundo Marco Lipay, urologista da Faculdade de Medicina do ABC (SP), a cada 100 casos de câncer registrados no Brasil, três são de pênis. "Um problema que poderia ser evitado com essa cirurgia simples cuja cicatrização acontece em uma semana", diz.

Agora, essa crença começa a ser questionada e os médicos estão divididos tanto quanto ficaram com relação a extrair amígdalas. "A circuncisão pode não ser necessária quando o adulto consegue retrair a pele do pênis para limpar a região e faz isso sistematicamente", diz José Pinus, cirurgião do hospital Albert Einstein e professor titular da Universidade Federal de São Paulo.

MORAL DA HISTÓRIA: o necessário é manter o pênis sempre de banho tomado e não necessariamente sem capuz. Mas que fique muito claro: em caso de fimose, dificuldade ou impossibilidade de retrair a pele que cobre a glande, a cirurgia é a única solução. ${ }^{13}$

Alguns temas interessantes podem ser trabalhados através desta passagem. Ela revela que o jornalista atua como disseminador e propagador de teorias científicas ou provindas de especialistas para o público leigo. ${ }^{14} \mathrm{O}$ texto apresenta a opinião de dois especialistas, um a favor da circuncisão em qualquer caso, como forma de prevenção, e um que defende a cirurgia somente quando necessário. $\mathrm{O}$ embate de opiniões coloca em questão a unidade da medicina em torno de uma questão, como a necessidade da circuncisão. Não há consenso de opiniões e os especialistas divergem entre si.

${ }^{13}$ VIP Exame, edição 160, ano 17, número 8, agosto de 1998, p.121.

${ }^{14}$ Ver GIDDENS, A. Modernity and Self Identity... Op. cit. 
Num outro plano, o repórter simplifica todo o debate no final do texto, condensando o que foi dito e resumindo o debate. Ao interpretar as opiniões por ele apresentadas, realiza dois movimentos centrais na prática jornalística: cria um texto informativo, baseado em opiniões de especialistas, e faz um texto agradável e fácil de ser lido.

Segundo Bourdieu ${ }^{15}$, este tipo de simplificação das opiniões dos especialistas, com o qual opera o jornalismo, faz parte de seu habitus específico, mas coloca em xeque a própria validade da ciência e sua capacidade de criar discursos críticos a respeito da realidade que sejam de impacto para o grande público, dado que este público consome em larga escala discursos de jornalistas. Para Giddens, esta vulgarização atua como um fator que reforça o contexto de reflexividade, servindo de referência para as pessoas que são constantemente obrigadas a operar escolhas baseadas em referências múltiplas e, muitas vezes, dissonantes.

É importante reter aqui que as teorias científicas sobre o corpo, presentes nas páginas de revistas, passam pelo crivo do jornalista, portanto, são constantemente reinterpretadas e reescritas. A inserção desses textos num mecanismo reflexivo de divulgação de teorias científicas e criação de referenciais passa sempre pelas subjetividades dos profissionais que preparam o material "jornalístico", que serve, de alguma forma, como referência para o leitor no que tange a teorias sobre o corpo.

Como tenho mostrado, a criação de um produto jornalístico envolve a tradução de conceitos e "fatos" em textos (no caso da revista) fáceis, agradáveis e interessantes. A criação do interesse por parte do jornalista (que envolve a constituição de um "leitor ideal", servindo de medida para o profissional do jornalismo da adequação de uma matéria ao leitor alvo) envolve recursos de linguagem que revelam conceitos, preconceitos e representações dos jornalistas. Portanto, toda análise de conteúdo que tenha

${ }^{15}$ Bourdieu, Pierre. Sobre a Televisão. Rio de Janeiro, Zahar, 1997. 
Corpo e masculinidade na revista VIP Exame

como base esse tipo de material deve levar em consideração esse fator.

\section{A masculinidade descentrada}

Os exemplos que vimos da revista VIP oferecem uma idéia de como a revista masculina pode ser analisada como fruto de uma prática social específica de produção - o jornalismo -, tendo como pano de fundo a discussão sobre a masculinidade e o corpo masculino. As características específicas do trabalho jornalístico, o habitus do jornalista, a forma como opiniões de especialistas e saberes científicos são mobilizados e reinterpretados no contexto de uma revista masculina oferecem elementos para compreender melhor as formas pelas quais a masculinidade contemporânea é constituída.

No discurso da revista, o homem moderno deve se preocupar com o corpo, com sua aparência, mas esta preocupação só faz sentido tendo em vista sua relação com a mulher. Este discurso sobre o leitor é construído a partir das diversas representações sobre o homem dos jornalistas, que no caso desta redação são homens e mulheres. A VIP é uma revista inserida num mercado, portanto, está em relação com várias outras publicações. Ela representa uma proposta de leitor particular, que se diferencia de outros por se identificar com o projeto editorial da VIP.

Ela não se coloca como "A Revista Masculina" e não se pretende legível para todos os homens do país. Seu interesse não é propor uma masculinidade única, mas um diferencial de masculinidade que não é o do leitor da Playboy, da Placar ou da $G$ Magazine. A pluralidade de públicos e de nichos de mercado está presente como pressuposto; a VIP se volta a uma fração que tem naquele projeto editorial uma visão específica da masculinidade bem sucedida.

Interpretar este contexto requer abandonar qualquer busca por uma essência da masculinidade, pensamento este que incorre 
no erro de pensar em termos de "essência" ou de "origem", reificando algumas características do homem como universais que são, assim, descontextualizadas. Em termos da teoria de gênero, pensar em qualquer experiência unificada perde de vista que sempre a experiência de um grupo específico está sendo colocada como a experiência genérica de todos, seja ela da "mulher" como categoria essencializada ${ }^{16}$ ou do homem, sendo que existem grupos subordinados e dominantes e que a categoria homem não é, portanto, de nenhuma forma homogênea. ${ }^{17}$

Para a interpretação dos dados que apresentei acima, me fundamento numa concepção de sujeito que não é unificado $e$, portanto, não possui atributos que the são essenciais ou que permanecem imutáveis. ${ }^{18}$ Dentro da Antropologia, posso citar autores que discutem as epistemologias do sujeito unificado em relação com outras epistemologias. Strathern ${ }^{19}$, trabalhando com a Melanésia, sugere que o conceito de sujeito, com todos os seus pressupostos, pertence a uma cosmologia específica e não pode servir de base de análise para outras sociedades de forma indiscriminada. Esta categoria está vinculada a contextos locais e não é válida de forma atemporal e metafísica.

Segundo Hall, a questão da identidade está no topo das preocupações da teoria social na atualidade, porque estamos atualmente num momento de transição, onde velhas referências que estabilizavam nossas percepções e metodologias perdem paulatinamente o sentido.

${ }^{16}$ Butlen, J. Gender Trouble... Op. cit.; DE LAURETIS, Teresa. Eccentric Subjects... Op. cit.

${ }^{17}$ Almeida, Miguel Vale de. Senhores de si. Lisboa, Fim de Século Edições Ltda., 1995; ver também ConNel, Robert. Políticas da masculinidade. Educação $e$ Realidade, 20(2), 1995, pp.185-206; e The Big Picture: Masculinities in recent world history. Theory and Society, 22(5), 1993, pp.597-623.

${ }^{18}$ ButLer, J. Gender Trouble... Op. cit.; GIDDENS, A. Modernity and Self Identity... Op. cit.; Hall, S. A Identidade Cultural na Pós-modernidade. Op. cit.

${ }^{19}$ STRATHERn, Marilyn. The Gender of the Gift. London, University of California Press, 1988. 
A questão da identidade está sendo extensamente discutida na teoria social. Em essência, o argumento é o seguinte: as velhas identidades, que por tanto tempo estabilizaram o mundo social, estão em declínio, fazendo surgir novas identidades $e$ fragmentando o indivíduo moderno, até aqui visto como um sujeito unificado. A assim chamada "crise de identidade" é vista como parte de um processo mais amplo de mudança, que está deslocando as estruturas e processos centrais das sociedades modernas e abalando os quadros de referência que davam aos indivíduos uma ancoragem estável no mundo social. ${ }^{20}$

A preocupação de Hall é investigar esta suposta crise de identidade, suas origens e suas conseqüências. Ele considera que as identidades modernas estão sendo descentradas, deslocadas e fragmentadas. Seu argumento principal é que estas referências, que nos forneceram âncoras de estabilidade, enquanto identidades que definiam aquilo que éramos no mundo - como classe, sexo, raça nação, etc. -, estão sendo deslocadas e fragmentadas. As mudanças que ocorrem na sociedade contemporânea colocam em xeque a estabilidade destas categorias com conseqüencias para a nossa sensação de bem estar no mundo.

Isto porque, ao mesmo tempo, se transformam as nossas identidades pessoais. Acaba-se o sentimento de segurança, nossa certeza enquanto sujeitos estáveis e integrados. ${ }^{21}$ Esta perda de um sentido integrado de si é o que ele chama de descentramento do sujeito. Este descentramento ocorre tanto no lugar do indivíduo em seu mundo social, quanto na sua intimidade ou "subjetividade". A crise de identidade atinge em cheio a própria noção de indivíduo portador de identidades e papéis estáveis e

${ }^{20}$ Hall, S. A Identidade Cultural na Pós-modernidade. Op. cit., p.7.

${ }^{21}$ Esta discussão está inspirada no conceito de incerteza existencial ou ontológica, elemento presente nas sociedades atuais, que compõe o argumento de Giddens a respeito da reflexividade na composição de identidades nas sociedades do capitalismo tardio. GIDDENS, A. Modernity and Self Identity... Op. cit. 
com uma subjetividade. Dessa forma, ele considera que o indivíduo contemporâneo não possui mais um senso de identidade fixo ou essencial.

A primeira (atualmente mais contestada) formulação de sujeito moderno nasce, segundo Hall, com o filósofo francês Renée Descartes, a partir de seu ceticismo metafísico decorrente do deslocamento de Deus como centro do Universo. Descartes estabelece a separação entre matéria e espírito, e busca dar explicação para as coisas pela redução aos seus elementos essenciais.

No centro da mente, colocou o sujeito individual, constituído por sua capacidade para raciocinar e pensar. "Cogito, ergo sum" era a palavra de ordem de Descartes:

"Penso, logo existo" (...). Desde então, esta concepção do sujeito racional, pensante e consciente, situado no centro do conhecimento, tem sido conhecida como o "sujeito cartesiano". ${ }^{22}$

Até o século XVIII, segundo Hall, era possível pensar nos grandes processos da vida moderna como centrados neste sujeito da razão cartesiana, mas a complexificação das sociedades industriais tornou esse sujeito unificado cada vez mais problemático e problematizado; pensemos, por exemplo, no advento da psicanálise no século XIX como um questionamento desse sujeito. Segundo Hall, as identidades foram se tornando cada vez mais coletivas também, se pensarmos em movimentos como o operário ou mesmo o feminista, nascidos nesse período. Segundo Hall, a concepção clássica do sujeito sociológico, que veio questionar a concepção cartesiana, foi formulada por G.H. Mead, C.H. Cooley e o interacionismo simbólico. A identidade é pensada dentro desta concepção, se formando na interação entre o eu e a sociedade. O sujeito ainda possui uma essência, ou um

${ }^{22}$ Hall, S. A Identidade Cultural na Pós-modernidade. Op. cit., p.27. 
eu real, como no Iluminismo, mas esta é formada e modificada num processo contínuo de relação com o mundo exterior.

O sujeito pós-moderno ou descentrado, segundo o autor, surge a partir do colapso das bases deste sujeito sociológico. As identidades não são mais unificadas, mas múltiplas, fragmentadas e compostas de partes contraditórias.

Correspondentemente, as identidades, que compunham as paisagens sociais "lá fora" e que asseguravam nossa conformidade subjetiva com as "necessidades" objetivas da cultura, estão entrando em colapso, como resultado de mudanças estruturais e institucionais. O próprio processo de identificação, através do qual nos projetamos em nossas identidades culturais, tornou-se mais provisório, variável e problemático. ${ }^{23}$

O sujeito pós-moderno, segundo Hall, não possui uma identidade fixa, seja ela imanente ou fruto de processos de estruturação social. Esta identidade é definida historicamente e não biologicamente. Diferentes identidades são assumidas em diferentes momentos, e estas não se unificam ao redor de uma concepção de um "eu" coerente. Por ser o indivíduo fragmentado, seu sentido de identificação está constantemente sendo deslocado.

Isso ocorre num momento histórico no qual se multiplicam sistemas de significação e representação cultural. ${ }^{24} \mathrm{O}$ sujeito assim confrontado com uma multiplicidade de referenciais possíveis perde qualquer senso de segurança existencial, pois quaisquer daquelas identidades poderiam lhe servir, pelo menos temporariamente.

Podemos pensar essa discussão como auxílio na compreensão daquilo que chamei de descentramento da masculinidade, na forma da multiplicação de revistas masculinas, cada uma com uma proposta diferente daquilo que é "ser homem". Esse contexto de pluralidade de propostas para o masculino perde o "ser homem" enquanto uma identidade fixa $e$

${ }^{23}$ ID., IB., p.12.

${ }^{24}$ ID., IB., p.13. 
estável. A masculinidade se fragmenta, levando à coexistência (não necessariamente pacífica) de diferentes modelos $e$ questionando a estabilidade de um modelo hegemônico único.

Hall se baseou em larga escala nas discussões sobre reflexividade no contexto pós-tradicional de Giddens para fundamentar sua concepção de sujeito. Segundo Giddens, a tradição é, por definição, um conjunto fixo de preceitos dentro dos quais o sujeito vive, preceitos que expressam a "verdade" das coisas e que adquirem um estatuto metafísico de realidade. $\mathrm{O}$ contexto atual é de multiplicidade e, ao invés de uma tradição como referencial único, temos múltiplos referenciais igualmente "legítimos". O sujeito, então, é forçado a fazer escolhas constantemente no decorrer do seu dia a dia; o estilo de vida se torna uma expressão da própria subjetividade do indivíduo. Ou seja, estilo de vida neste conceptual não se refere somente à esfera do consumo ou da aparência, mas sim à narrativa de vida, do self, do sujeito. Construir estilos de vida aqui pode ser pensado como constituir subjetividades. Na definição do autor:

\section{A lifestyle can be defined as a more or less integrated set of practices which an individual embraces, not only because such practices fulfil utilitarian needs, but because they give material form to a particular narrative of self-identity. ${ }^{25}$}

O estilo de vida pressupõe um aglomerado de hábitos $e$ predisposições $e$, portanto, tem uma certa unidade. ${ }^{26}$ Isto possibilita ao indivíduo uma sensação de segurança ontológica ou existencial, pois é a busca de um conjunto de referências mais ou menos fixas num mundo povoado pela incerteza $e$ pelo contingente. No entanto, mesmo tendo esta coerência, Giddens reafirma que todas as opções feitas são passíveis de serem questionadas e revistas reflexivamente, incorporando outros

${ }^{25}$ GIDDENS, A. Modernity and Self Identity... Op. cit., p.81.

${ }^{26}$ ID., IB., p. 82 . 
referenciais. Ele coloca também que nem todas as opções estão disponíveis para todos, e que a escolha, portanto, não se faz completamente livre de coerções. Há elementos de classe social, maior visibilidade social de certos estilos de vida sobre outros, e pressões de grupos de convivência.

A reflexividade como forma de se constituir a subjetividade se estende por todas as áreas da pessoa, inclusive o corpo. $\mathrm{O}$ corpo, na situação contemporânea, se torna parte do mecanismo da reflexividade, e ao constituir uma identidade para si, a pessoa constitui um corpo específico como parte deste processo.

What does it mean to say that the body has become part of the reflexivity of modernity? Body regimes and the organisation of sensuality in high modernity become open to continuous reflexive attention, against the backdrop of plurality of choice. Both life planning and the adoption of lifestyle options become (in principle) integrated with bodily regimes. It would be quite short-sighted to see this phenomenon only in terms of changing ideals of bodily appearance (such as slimness or youthfulness), or as solely brought about by the commodifying influence of advertising. We become responsible for the design of our own bodies, and in a certain sense noted above are forced to do so the more post-traditional the social-contexts in which we move. ${ }^{27}$

Bourdieu também trata do tema de estilos de vida, a partir do seu conceito de habitus.

Às diferentes posições no espaço social correspondem estilos de vida, sistemas de desvios diferenciais que são a retradução simbólica de diferenças objetivamente inscritas nas condições de existência. As práticas e as propriedades constituem uma expressão sistemática das condições de existência (aquilo que chamamos de estilos de vida) porque

${ }^{27}$ ID., IB., p.102. 
Marko Monteiro

são o produto do mesmo operador prático, o habitus, sistema de disposições duráveis e transponíveis que exprime, sob a forma de preferências sistemáticas, as necessidades objetivas das quais é produto. ${ }^{28}$

Para Bourdieu o estilo de vida não se separa do habitus do sujeito, que é expressão simbólica das suas condições de existência. A partir de suas condições objetivas, o que supõe uma certa inserção diferenciada de classe, acesso a bens materiais $e$ simbólicos, forma-se um habitus particular que engendra um certo estilo de vida. Não se trata de uma determinação simples das condições materiais por sobre as formulações simbólicas do habitus. O habitus não é mera formulação simbólica de uma realidade material, mas é um devir, que inclui e pressupõe uma ação e uma formulação sobre a ação. Este devir forma o habitus e estruturas cognitivas distintas de gosto, que diferencia distintos estilos de vida. Para Bourdieu, mencionando a dialética da distinção, a classe mais alta busca distanciar seus valores estéticos das necessidades materiais e do gosto das classes baixas, afim de manter uma distância simbólica que reafirma um valor superior aos valores desta classe dominante.

Portanto, o habitus vai determinar o gosto de classe e o estilo de vida de um grupo. Seguindo a leitura que Giddens faz das formulações de Bourdieu, variações de estilo de vida entre grupos são elementos fundamentais de estratificação, ou de diferenciação de status entre os grupos, e não meramente resultado de diferenças de classe e de inserção na produção.

Bourdieu também faz uso do conceito de habitus para pensar as relações entre os sexos ${ }^{29}$, dando pistas importantes para perceber como o corpo é mobilizado na constituição de identidades pessoais. A noção de habitus, aplicada aos regimes

${ }^{28}$ BouRdiEU, Pierre. Gostos de classe e estilos de vida. In: OrTIZ, Renato. (org.) Pierre Bourdieu. São Paulo, Ática, 1983, p.82.

${ }^{29}$ Bourdieu, Pierre. A dominação masculina. Educação e Realidade, 20(2), 1995, pp.133-184; La Domination Masculine. Paris, Seuil, 1998. 
Corpo e masculinidade na revista VIP Exame

corporais e de identidade, sugere um funcionamento estruturalista, ou fora do alcance do indivíduo do que a noção de reflexividade. Apesar de a formulação do conceito por parte de ambos os autores dar margem para tais interpretações, creio que em ambos os casos as semelhanças justificam a aproximação que faço entre os dois conceitos.

Bourdieu dialoga com as teorizações feministas, e ao falar de como as "identidades de gênero" se fixam no corpo sob a forma de habitus, formula também uma crítica à naturalização da distinção entre os sexos (a dualidade homem/mulher) e uma crítica à inscrição desta dominação social no âmbito de uma essência, com raízes metafísicas ou biológicas. Ambas estas temáticas são centrais nas formulações da teoria feminista contemporânea ${ }^{30}$ :

O habitus produz construções socialmente sexuadas do mundo e mesmo do próprio corpo que, sem serem representações intelectuais, não são menos ativas, $e$ respostas sintéticas e adaptadas que, sem serem fundadas no cálculo explícito de uma consciência mobilizando uma memória, não são tampouco o produto do funcionamento cego de mecanismos físicos ou químicos capazes de dispensar o espírito. Através de um trabalho permanente de formação, de Bildung, o mundo social constrói o corpo, ao mesmo tempo como realidade sexuada e como depositário de categorias de percepção e de apreciação sexuantes, que se aplicam ao próprio corpo na sua realidade biológica. ${ }^{31}$.

Vemos aqui que Bourdieu se depara com a oposição, arraigada no pensamento social, entre material/simbólico, objetivo/subjetivo. Seu conceito de habitus é uma tentativa de ir além desta oposição, não sendo fruto de uma escolha livre e

${ }^{30}$ Butlen, J. Gender Trouble... Op. cit.; De Lauretis, Teresa. Eccentric Subjects... Op. cit.

${ }^{31}$ Bourdieu, P. A dominação masculina. Op. cit., 1995, p.144. 
Marko Monteiro

racional, mas não sendo simples determinação biológica. O habitus é um constante devir, um constante Bildung, que constrói a realidade ao mesmo tempo em que estrutura a sua percepção. Como pensar as determinações da estrutura sem perder de vista o aspecto do agenciamento, das respostas e dos investimentos diferenciados dos sujeitos confrontados com essas estruturas? Ao mesmo tempo, como pensar no agenciamento sem recolocar o sujeito cartesiano, completamente racional e pré-discursivo ${ }^{32}$

Scott Lash ${ }^{33}$ menciona que tanto Giddens como Bourdieu foram chamados "teóricos da estruturação", no sentido de que formularam teorias nas quais o ator social está engajado na construção de estruturas. Lash também considera que em Bourdieu há uma dualidade reflexiva no seu pensar sobre a estrutura, pois esta é tanto o resultado da ação como o meio reflexivo desta ação. Assim, Bourdieu se distanciaria tanto de uma visão radicalmente estruturalista como de Lévi-Strauss, assim como de teóricos de uma ação racional. O sujeito de Bourdieu, para Lash, está inserido desde já numa matriz de práticas estabelecidas, portanto, sua escolha $e$ sua ação não estão completamente separadas da estrutura. Ele explicita melhor este ponto ao falar da teoria da ação:

O habitus está, portanto, muito distante da "ação". A teoria da ação fala a linguagem do "ato unitário"; o habitus, a linguagem das atividades contínuas. A teoria da ação pressupõe, pelo menos implicitamente, um ator desincorporado, minimizador do custo e maximizador do benefício, e com preferências determinadas. O habitus só existe quando situado em seu "mundo". A teoria da ação é freqüentemente "construtivista", em que a ação é a força motriz que está por trás da estrutura, como, por exemplo, em "redes de atores". O habitus, ao contrário, supõe um

\footnotetext{
32 Butler, J. Gender Trouble... Op. cit..

${ }^{33}$ LASH, Scott. A reflexividade e seus duplos: estrutura, estética e comunidade. In: GidDEnS, A. Modernização Reflexiva... Op. cit., p.184.
} 
Corpo e masculinidade na revista VIP Exame

certo "arremessar-se" em uma rede de práticas e
significados já existentes.

A concepção cartesiana de sujeito, como já foi assinalado, apresenta a unidade e coerência do sujeito como dados metafísicos e o sujeito como sendo um ente unificado $e$ para sempre coerente, a partir do fato que ele preexiste ao seu corpo (separação entre corpo e espírito). Uma leitura de teóricos contemporâneos, desde Giddens e Bourdieu até feministas como Butler, De Lauretis e Strathern, sugere que, ao pensarmos em termos de "sujeitos descentrados", devemos ressaltar a importância também do corpo como atuante sobre a constituição das identidades contemporâneas, que são por isto mesmo múltiplas, mutáveis, por vezes incoerentes e que não permanecem necessariamente as mesmas durante toda a vida de uma pessoa.

O cuidado com o corpo, a constituição reflexiva deste corpo $^{35}$ se torna elemento importante da constituição dos sujeitos contemporâneos. Como vemos nas páginas da revista e nas discussões de seus editores e repórteres, a preocupação com a aparência se torna um fator decisivo na fórmula editorial da VIP, se diferenciando de outra revistas que poderiam considerar esse tipo de preocupação como supérflua, ou mesmo inadequada enquanto traço de masculinidade. Este tipo de incoerência no mercado editorial é ilustrativo do que Giddens examina como sendo o contexto de dúvida radical e de reflexividade na vida contemporânea.

Ou seja, não existem referências imutáveis ou fixas de identidade, elas são múltiplas e colocadas em questão constantemente. Da mesma forma as revistas divergem entre si, colocando em questão, constantemente, conceitos a respeito do corpo e da aparência. A cada avanço tecnológico que surge, esses conceitos podem ser completamente revisados, como é o caso da

${ }^{34}$ LASH, S. A reflexividade e seus duplos... Op. cit., p.187.

${ }^{35}$ GIDDENS, A. Modernity and Self Identity... Op. cit. 
ingestão de colesterol e de alimentos específicos como praticas corretas para um corpo saudável.

A preocupação com a aparência foi, tradicionalmente, prerrogativa da feminilidade, tendo conseqüencias nefastas para as mulheres como discute Susan Bordo no caso das mulheres histéricas no final do século passado e das epidemias de bulimia $e$ de anorexia nervosa em sociedades industrializadas da atualidade. ${ }^{36}$ Para esta autora, o corpo é uma forma simbólica poderosa e não somente um texto; inspirada em Bourdieu ${ }^{37}$, ela diz que o corpo é um locus prático e direto do controle social.

Bordo analisa a questão do cuidado com o corpo principalmente a partir da noção foucaultiana de corpo dócil, ou de corpo que é controlado pela epistème, transformado, vigiado. Em contraste, Giddens, já discutido a partir de seu conceito de reflexividade, critica as noções foucaultianas como relegando a liberdade do sujeito para um segundo plano, não deixando espaço para o sujeito e sua agency, ou sua capacidade de escolher, de agir, mesmo que imerso em estruturas sociais.

Para Bordo, no entanto, a noção de corpo dócil se torna um meio poderoso de renovar o campo do feminismo, ao possibilitar uma análise do corpo que capture toda sua riqueza como locus de controle social e de criação de normas para o sujeito. A partir do controle do corpo, a mulher para Bordo se torna esse sujeito específico "mulher" (e não "homem" ou qualquer outra identidade) a partir de um controle rigoroso de seu corpo - seja por dietas, cirurgias estéticas ou através da moda -, que é veiculado nos dias atuais principalmente a partir de imagens padronizadas que circulam na mídia, em ensaios de moda, desfiles, filmes, novelas e revistas.

Ambas discussões apresentam conseqüências no que se refere à centralidade do corpo na constituição da identidade. Se

${ }^{36}$ BORDO, Susan. The Body and the Reproduction of Femininity... Op. cit.

${ }^{37}$ Bourdieu, Pierre. Outline of a Theory of Practice. Cambridge, Cambridge University Press, 1997 [1972]. 
Giddens pode ser criticado por um suposto voluntarismo e Bordo por um excesso de preocupação com a dominação, ambos argumentam que a constituição do corpo através de práticas de controle, largamente influenciadas por imagens e informações provenientes da mídia, deve ser retomada como foco central na discussão da formação de sujeitos contemporâneos. Bordo chama corretamente a atenção para o maior peso destas práticas - tais como dietas - na vivência da feminilidade, algo que Giddens ignora, mas creio que na VIP temos exemplos de como estes saberes sobre o corpo começam a colonizar também os mundos masculinos.

A importância do corpo para a antropologia é central desde o século passado, segundo Bryan Turner ${ }^{38}$, diferentemente da Sociologia, que enquanto disciplina se centrou mais na discussão a respeito da particularidade do moderno. Para a Antropologia sempre foi importante perceber como as normas, diferenças de status e de lugar social eram inscritas nos corpos de sociedades "pré-modernas", preocupação que hoje é explorada também com respeito às sociedades industriais.

A centralidade do corpo na teoria antropológica é objeto de discussão de autores como Thomas Csordas. ${ }^{39}$ Esse último, baseado em Merleau-Ponty e Bourdieu, desenvolveu o conceito de embodiment, ou de incorporação, base para uma discussão sobre o corpo como base existencial da cultura. Ou seja, o corpo deve ter centralidade nos estudos sobre a cultura, e não ser pensado somente como objeto a ser estudado em relação a esta. Este tipo de movimento em direção ao corpo critica necessariamente a divisão cartesiana entre corpo e espírito, entre mente e carne, que percebe o corpo como produto secundário ou como subjugado às representações mentais do sujeito. $\mathrm{O}$ corpo

${ }^{38}$ TURNER, Bryan S. Recent Developments in the Theory of the Body. In: Featherstone, M. et alii. (eds.) The Body: Social Process and Cultural Theory. London, Sage, 1991, pp.1-35.

${ }^{39}$ CSORDAS, Thomas. Embodiment as a paradigm for Anthropology. Ethos 18, 1990, pp.5-47. 
Marko Monteiro

cartesiano, por assim dizer, é representado a partir da cultura. Para o tipo de análise que pretende Csordas, o corpo se torna base das representações e as constrói por sua vez, ao invés de ser mero objeto.

$\mathrm{O}$ autor discute Merleau-Ponty e Bourdieu a partir das suas tentativas de criticar as separações entre sujeito e objeto e entre estrutura e prática, respectivamente. Segundo Csordas, ambos se valem do conceito de incorporação para atingir estes objetivos. Para o autor, Merleau-Ponty critica a existência de objetos anteriores à percepção, que começa no corpo. $\mathrm{O}$ corpo no mundo é o início da reflexão a respeito das coisas e não seu objeto; os objetos não são dados empíricos que se colocam à percepção, mas são resultados desta percepção que é incorporada, parte de um corpo no mundo. Para Bourdieu o conceito de habitus, ou de predisposições incorporadas, busca terminar com a separação entre estruturas sociais e práticas do sujeito. O habitus incorporado é ao mesmo tempo onde as práticas do sujeito acontecem e onde estão localizadas as normas e distinções sociais.

A antropóloga Nancy Scheper-Hughes ${ }^{40}$ trabalha na mesma direção, pensando o corpo como central à análise cultural. Sua discussão, pautada pela Antropologia Médica, critica a oposição cartesiana entre corpo e espírito afim de explorar melhor as formas como o corpo participa de processos sociais de formas mais importantes do que como suporte de interpretações ou representações.

As both medical anthropologists and clinicians struggle to view humans and the experience of illness and suffering from an integrated perspective, they often find themselves trapped by the Cartesian legacy. We lack a precise vocabulary with which to deal with mind-body-society interactions and so are left suspended in hyphens, testifying

${ }^{40}$ SCHEPER-HughES, Nancy e LOCK, Margaret. The Mindful Body: A Prolegomenon to Future Work in Medical Anthropology. Medical Anthropology Quarterly, 1(1), 1987, pp.6-39. 
Corpo e masculinidade na revista VIP Exame

the disconnectedness of our thoughts. We are forced to resort to such fragmented concepts as the bio-social, the psycho somatic, the somato-social as altogether feeble ways of expressing the myriad ways in which the mind speaks through the body, and the ways in which society is inscribed on the expectant canvas of human flesh. ${ }^{41}$

\section{Conclusões}

Quero argumentar, a título de conclusão para este trabalho, que um discurso específico sobre o corpo masculino, presente na $V I P$, define uma postura específica da revista com relação à masculinidade e ao corpo masculino. Por isso mesmo, não podemos analisar esse tipo de material a partir de uma concepção cartesiana de sujeito, que separa corpo e mente e coloca o corpo em segundo plano, subordinado ao espírito, que representa o sujeito racional $e$ unificado, sem empobrecer enormemente a análise. O corpo é mutável, e é na constituição reflexiva do corpo, entre outras instâncias, que o homem contemporâneo se constitui. As formas de manutenção e monitoramento do corpo são centrais na constituição de uma subjetividade específica do homem. A constituição de uma masculinidade de forma reflexiva requer uma constituição reflexiva do corpo.

O corpo se torna elemento importante da reflexividade, pois é através da criação e da recriação de um corpo que masculinidades específicas se articulam e se constituem enquanto identidade para o sujeito. Longe de se limitar a referências semiológicas, as imagens e mensagens textuais da revista dizem respeito à constituição do corpo do seu leitor. A partir de dicas e de matérias sobre o corpo, a revista busca articular uma representação específica em torno do corpo masculino, que corresponde ao "homem VIP", o homem que, segundo os editoriais, se preocupa com a aparência e a saúde, assim como

${ }^{41}$ ID., IB., p.10. 
com a moda e a beleza, sem deixar de ser másculo e se interessar primordialmente por mulheres.

As matérias articulam referências da ciência, do esporte e da psicologia, juntamente com as opiniões e vivências dos próprios profissionais da revista, oferecendo ao leitor opiniões $e$ "informação" pautadas por especialistas. Estas matérias e a informação assim produzida nas páginas da revista se torna parte do processo de reflexividade ao servir de referência aos leitores, ao fornecer "informação" para os leitores que podem servir de base para suas escolhas pessoais no que diz respeito à produção reflexiva de seu corpo. Esta produção ocorre através de práticas exercícios para mudar a forma e aumentar massa muscular, ingestão de substâncias que melhoram a ereção e diminuem a queda capilar e realização de cirurgias plásticas.

Tais práticas são exploradas pela revista no sentido de informar ao leitor sobre beleza e saúde e são apresentadas num contexto de idéias que compõe a VIP. Esta revista, como qualquer outra, tem uma proposta editorial específica e busca leitores específicos. É a partir da proposta editorial da revista e das representações sobre o leitor, produzidas no interior da redação, que se apresentam as opiniões científicas, embasando reportagens e matérias. Portanto, a "informação" produzida pelos jornalistas e distribuída pela revista, baseada em especialistas - médicos, cirurgióes plásticos e treinadores esportivos - é, por virtude da especificidade do trabalho jornalístico, carregada de valores a respeito do que seja o homem, a masculinidade e seu corpo. Estas opiniões se tornam referência para o leitor quando este consome a revista publicada.

A fragmentação ou descentramento das masculinidades ocorre num período histórico onde o próprio mercado editorial brasileiro se fragmenta. ${ }^{42} \mathrm{~A}$ constante busca de novidades e de

42 MIRA, Maria Celeste. O Leitor e a Banca de Revistas: O caso da Editora Abril. Tese de Doutorado em Sociologia do Instituto de Filosofia e Ciências Humanas da Unicamp, sob orientação do Prof. Dr. Renato Ortiz, Campinas, 1997. 
Corpo e masculinidade na revista VIP Exame

novas propostas editoriais, que atendam a públicos cada vez mais específicos e segmentados, faz parte de uma lógica de mercado que valoriza os interesses específicos do leitor em detrimento de uma massificação do produto padronizado. ${ }^{43}$ Esta segmentação cria uma multiplicidade de vozes e pode ser interpretada dentro do que Giddens chama do contexto de dúvida radical que permeia a contemporaneidade e fornece a base para o surgimento da reflexividade.

Esta multiplicidade de vozes não existe fora de um contexto de desigualdade que a fundamenta, agindo também como interferência. Algumas formas são vistas como mais adequadas para contextos específicos do que outras. Ou seja, a preocupação com a aparência é legítima, ou mesmo pressuposta, em algumas camadas da sociedade e em algumas publicações $e$ não em outras. No caso da VIP, voltada para homens heterossexuais, de bom nível financeiro, a questão da boa aparência é colocada constantemente como sintoma de uma masculinidade bem sucedida e a preocupação com o corpo é colocada como central na constituição do indivíduo masculino.

${ }^{43}$ NIXON, Sean. Hard Looks: Masculinities, Spectatorship and Contemporary Consumption. New York, St. Martin's Press, 1996. 